\title{
Genetic Diversity Analysis in Bread Wheat (Triticum aestivum L.em.Thell.) for Yield and Physiological Traits
}

\author{
Santosh, J.P. Jaiswal*, Anupama Singh and Naveen Chandra Gahatyari
}

Department of Genetics and Plant Breeding, College of Agriculture, Govind Ballabh Pant

University of Agriculture \& Technology Pantnagar, Udham Singh Nagar, Uttarakhand, India

*Corresponding author

\begin{tabular}{|l|}
\hline Ke y w o r d s \\
Bread wheat, \\
genetic divergence, \\
D2-statistics, \\
clustering and \\
SPAD
\end{tabular}

\section{Keywords}

Bread wheat, D2-statistics, clustering and SPAD

Article Info

Accepted:

Available Online:

10 February 2019

\section{A B S T R A C T}

The present investigation was carried out with 32 diverse genotypes of bread wheat in completely randomized block design with 3 replications at Norman E. Borlaug Crop Research Centre, G.B. Pant University of agriculture \& Technology Pantnagar for screening the genetic diversity for yield and physiological traits under normal sown condition. The observations were recorded on 16 agronomic traits and 3 physiological traits. The statistical analysis for genetic divergence was done using Mahalanobis- ${ }^{2}$ statistics and clustering of genotypes was done using Tocher method. On the basis of genetic diversity analysis, it was found that the maximum percent contribution towards genetic divergence was from grain yield and minimum by harvest index and spikelet number per spike. Clustering of genotypes revealed that cluster-II has maximum number of genotypes (13) and clusters IV, V and VI each has single genotype only. The highest intra-cluster distance was exhibited by cluster-III (583.84) revealing maximum genetic divergence among its constituents. The highest inter-cluster distance was found between clusters V and VI (1924.88) and the lowest was between cluster-I and II (410.95). Cluster-I exhibited highest cluster means for most of the agronomic traits like grain weight per spike, biological yield per plant and grain yield per plot while clusters-IV and V revealed highest cluster means for physiological traits like canopy temperature depression and SPAD (chlorophyll content) value. The genotypes bearing the desired values from different clusters can be exploited in future breeding programme for the improving the wheat genotypes for yield and physiological traits.

\section{Introduction}

Wheat (Triticum aestivum L.) is the most widely grown crop and an essential component of the global food security mosaic, providing one-fifth of the total calories for the world's population. India is second largest producer of wheat in the world. The area, production, and productivity of wheat in India in 2017-18 was 29.58 million ha, 99.7 million ton and 33.71 qtls/ha, respectively (ICARIIWBR, 2018). It is grown in all the regions of the country and the states, namely, Uttar Pradesh, Punjab, Haryana, Madhya Pradesh, Rajasthan, Bihar, Maharashtra, Gujarat, West Bengal, Uttarakhand and Himachal Pradesh 
together contribute about $98 \%$ to the total wheat production of the country and play an important role of supplying carbohydrate and protein (Tewari et al., 2015).

Genetic diversity and relationship among genotypes is a prerequisite for any successful breeding programme. Genetic diversity of plants determines their potential for improved efficiency and hence their use for breeding, which eventually may result in enhanced food production. Evaluation of genetic diversity levels among adapted, elite germplasm can provide predictive estimates of genetic variation among segregating progeny for pure-line cultivar development. Genetic similarity or dissimilarity can be compared by genetic distance between different individuals. Genetic distance can be used to measure the genetic divergence between different sub-species or different varieties of a species. The parents having more genetic distant relationship result into higher heterotic expression in F1 and greater amount of genetic variability in segregating populations (Shekhawat et al., 2001). Jaiswal et al., (2010) studied genetic diversity for yield and yield contributing traits in 300 indigenous germplasm of bread wheat. On the basis of dissimilarity coefficient, these genotypes were grouped into 23 clusters.

The genetic diversity of genotypes is not always based on factors such as geographical diversity, place of release and ploidy level etc. Hence characterization of genotypes should be based on statistical procedures. Different statistical methods have been developed to assess the genetic diversity such as $\mathrm{D}^{2}$ statistics and hierarchical ecludean cluster analysis. These methods determine the genetic divergence using the similarity or dissimilarity based on aggregate effect of different economic important traits. Some appropriate methods, cluster analysis, PCA and factor analysis, for genetic diversity identification, parental selection, tracing the pathway to evolution of crops, centre of origin and diversity, and study interaction between the environment are currently available (Bhatt, 1970; Carves et al., 1987; Mohammadi and Prasanna, 2003). Precise information on nature and degree of genetic divergence helps the plant breeder in selecting the genetically diverse parents for the purposeful hybridization (Arunachalam, 1981). Genetic improvement of yield especially in self-pollinated crops depends on nature and amount of genetic diversity (Joshi and Dhawan, 1966).

One of the important approaches to wheat breeding is hybridization and subsequent selection. Parents' choice is the first step in plant breeding program through hybridization. In order to obtain transgressive segregants, genetic distance between parents is necessary (Joshi et al., 2004). Higher heterosis in progeny can be observed with higher genetic distance between parents (Joshi and Dhawan, 1966). Estimation of genetic distance is one of appropriate tools for parental selection in wheat hybridization programs.

\section{Materials and Methods}

The initial research related to screening was carried out in the experimental fields of N.E. Borlaug Crop Research Centre (NEBCRC), G.B. Pant University of Agriculture and Technology. Pantnagar, Uttarakhand, India during rabi 2014-15. The experimental material consists of 32 genotypes of bread wheat including 3 checks namely HD 2967, PBW 343 and C 306 (Table 1). The experiment was laid out in randomized complete block design (RBD) with three replications. Each entry was planted in 5 meter long four rows plot. The rows were spaced $20 \mathrm{~cm}$ apart. All the recommended package of practices for wheat was followed to raise a healthy crop. All the morho- 
agronomic and physiological observations on most of the characters were recorded on single plant basis except for days to 75 per cent heading, maturity and canopy temperature depression (CTD). Five representative plants from each plot were randomly selected and tagged for recording the observations on single plant basis. Average data from selected plants in respect of different characters were used for statistical analysis. The observations were recorded for the sixteen morpho-agronomic traits viz., days to $75 \%$ heading, days to $75 \%$ anthesis, days to $75 \%$ maturity, plant height, peduncle length, number of tillers per plant, grain filling duration, spike length, number of spikelets per spike, number of grains per spike, grain weight per spike, 1000 grain weight, biological yield per plant, grain yield/plot, harvest index and three physiological traits, canopy temperature depression (CTD), relative water content percent $(\mathrm{RWC} \%)$ and chlorophyll content (SPAD value) of leaf. Canopy temperature was recorded 4 times at the interval of 10 days at different growth stages of the crop from the start of flowering (GS61) to early dough stage (GS 83 as per Zodoks et al., 1974) and it was mentioned as canopy temperature -I (CT -I), canopy temperature-II (CT-II), canopy temperatureIII (CT-III) and canopy temperature-IV (CTIV), and difference between canopy temperature and ambient temperature was calculated and it was designated as canopy temperature depression (CTD I, II, III and IV). The statistical analysis for genetic divergence was done using Mahalanobis- $\mathrm{D}^{2}$ statistics (Mahalanobis, 1936) and clustering of genotypes was done using Tocher method (Rao 1952).

\section{Results and Discussion}

\section{Cluster information}

In the present study, all the 32 genotypes were grouped into six clusters (Figure 1 and Table
2) suggesting considerable amount of genetic diversity in the material. The cluster pattern of the genotypes showed non-parallelism between geographic and genetic diversity (Singh et al., 2009). The cluster-II has highest number of genotypes (13) followed by cluster-III (10) and cluster-I (6) while clusters IV, V and VI each has single genotype only. The cluster-I consists of genotypes viz., BWL 0814, HD 2967, Bacanora 88, PBW-343, Chirya-3 and Babax. The genotypes BWL1793, IEPACA RABE, BWL-9022, HI-1563, Raj-4083, HD-2864, DBW-14, Seri-82, Othery Egypt, WH-730, Tepoko, PBN-51, Dharwar Dry were grouped into cluster-II. Cluster -III having the ten genotypes, namely, BWL-1771, Salembo, BWL-0924, CUS/79/PRULLA, Raj-4037, IC-118737, K9465, Giza-155, C-306 and Ariana-66. Cluster-IV has Sonora-64, cluster-V has Raj3765 and cluster VI has IC-532653 genotypes. The pattern of distribution of genotypes in different cluster exhibited that geographical diversity was not related to genetic diversity as genotypes of same geographical region were grouped into different clusters and vice-versa (Kumar et. al. 2009, Rahman et al., 2015).

\section{Percent contribution of different characters towards genetic divergence}

On the basis of genetic diversity analysis, the maximum percent contribution (Figure 2 and Table 3) towards genetic divergence was from grain yield per plot i.e. $51.01 \%$ followed by CTD-I (21.71\%), CTD-IV (10.28\%), SPAD value $(7.26 \%)$, RWC (3.43\%), biological yield per plant $(2.82 \%)$, CTD-III $(2.22 \%)$, CTD-II (1.01\%) and minimum by harvest index and number of spikelets per spike i.e. $0.20 \%$. The remaining characters did not show contribution towards genetic divergence. The contribution of number of spikelet per spike has also been observed by Dobariya et al., (2006) and biological yield per plant by Arya et al., (2017). The 
contribution of various characters towards the expression of genetic divergence should be taken into account as a criterion for choosing parents for crossing programme for the improvement in such characters.

\section{Intra and inter-cluster distances}

The intra and inter-cluster distances (Table 3) were calculated to determine the genetic relationship among the individuals within a cluster and between members of different clusters. The highest average intra-cluster distance was exhibited by cluster-III (583.84) followed by cluster-II (353.12), cluster-I (139.51) suggesting that genotypes in clusterIII were relatively more diverse than the genotypes in other clusters.

Inter-cluster distance is the main criterion for selection of genotypes using $\mathrm{D}^{2}$ analysis (Khare et al., 2015). The genotypes belonging to those clusters having maximum intercluster distance are genetically more divergent and hybridization between these genotypes of different clusters is likely to produce wide variability with desirable individuals (Gartnar et al., 1989 and Singh et al., 2006). The highest inter-cluster distance was found between clusters-V and VI (1924.88) suggested a genetically distant relationship between these two clusters and high degree of genetic diversity among the genotypes followed by clusters-I and IV (1879.23), clusters-II and IV (1518.53), clusters-III and VI (1325.23), clusters-I and IV (1163.56), clusters-III and V(1105.93), clusters-I and V (996.05), clusters-III and IV (970.10), clusters-IV and VI (957.17), clusters-II and III (665.03), clusters-II and IV (638.41), clusters-IV and V (614.64), clustersI and III (597.46), clusters-II and IV (596.43) while the lowest inter-cluster distance was observed between clusters-I and II (410.95) suggested a closer relationship between these two clusters and low degree of genetic diversity among the genotypes. Presence of substantial genetic diversity among the parental material screened in the present study indicated that this material may serve a good source for selecting the diverse parents for hybridization programme. In order to increase the possibility of isolating good transgressive segregants in the segregating generations it would be logical to attempt crosses between the diverse genotypes belonging to clusters separated by large inter-cluster distances.

\section{Cluster means}

Cluster means were calculated for all the physiological and agronomic characters which exhibited considerable differences among the clusters. The mean performance of the clusters (Table 4) was used to select genetically diverse and agronomically superior genotypes out of 32 genotypes studied. The highest cluster mean for days to $75 \%$ flowering was exhibited by cluster-VI (95.33) followed by cluster-III (90.30), cluster-I (89.89), cluster-II (84.41), cluster$\mathrm{V}(81.33)$ and the lowest by cluster-IV (74.0). The highest cluster mean for days to $75 \%$ anthesis was observed in cluster-VI (101.67) followed by cluster-III (94.53), cluster-I (94.00), cluster-II (91.64), cluster-V (89.67) and the lowest by cluster-IV (84.67). The highest cluster mean for day to $75 \%$ maturity was observed in cluster-VI (142.0) followed by cluster-I (133.44), cluster-III (132.23), cluster-V (132.00), cluster-II (131.79) and the lowest by cluster-IV (126.67).

The highest cluster mean for grain filling duration was observed in cluster-V (42.33) followed by cluster-IV (42), cluster-VI (40.33), cluster-II (40.15), cluster-I (39.44) and the lowest by cluster-III (37.93).The highest cluster mean for plant height was exhibited by cluster-VI (113.67) followed by cluster-III (105.59), cluster-I (97.09), clusterII (97.03), cluster-V(95.73) and lowest was exhibited by cluster-IV (90.07). 
Table.1 List of genotypes/varieties

\begin{tabular}{|c|c|c|c|c|c|c|c|}
\hline $\begin{array}{l}\text { SI. } \\
\text { No. }\end{array}$ & Genotype & $\begin{array}{l}\text { Sl. } \\
\text { No. }\end{array}$ & Genotype & $\begin{array}{l}\text { Sl. } \\
\text { No. }\end{array}$ & Genotype & $\begin{array}{l}\text { Sl. } \\
\text { No. }\end{array}$ & Genotype \\
\hline 1. & PBN-51 & 9. & IC-532653 & 17. & HI-1563 & 25. & SONORA-64 \\
\hline 2. & BWL-1793 & 10. & $\begin{array}{l}\text { DHARWAR } \\
\text { DRY }\end{array}$ & 18. & HD-2864 & 26. & $\begin{array}{l}\text { BACANORA- } \\
88\end{array}$ \\
\hline 3. & BWL-0814 & 11. & GIZA-155 & 19. & RAJ-3765 & 27. & SALEMBO \\
\hline 4. & $\begin{array}{l}\text { HD-2967 } \\
\text { (check) }\end{array}$ & 12. & ARIANA-66 & 20. & RAJ -4083 & 28. & CHIRYA-3 \\
\hline 5. & BWL-1771 & 13. & $\begin{array}{l}\text { PBW-343 } \\
\text { (check) }\end{array}$ & 21. & DBW-14 & 29. & BWL-9022 \\
\hline 6. & BWL-0924 & 14. & BABAX & 22. & WH-730 & 30. & $\begin{array}{l}\text { CUS/79/PRULL } \\
\text { A }\end{array}$ \\
\hline 7. & $\begin{array}{l}\text { C-306 } \\
\text { (check) }\end{array}$ & 15. & $\begin{array}{l}\text { IEPACA } \\
\text { RABE }\end{array}$ & 23. & RAJ-4037 & 31. & K-9465 \\
\hline 8. & IC-11873 & 16. & $\begin{array}{l}\text { OTHERY } \\
\text { EGYPT }\end{array}$ & 24. & SERI-82 & 32. & TEPOKO \\
\hline
\end{tabular}

Table.2 Distribution pattern of 32 genotypes under different clusters

\begin{tabular}{|c|c|c|}
\hline Clusters & $\begin{array}{l}\text { Number } \\
\text { genotypes }\end{array}$ & Name of genotypes \\
\hline Cluster-I & 6 & $\begin{array}{l}\text { BWL-0814, HD-2967, Bacanora-88, PBW-343, Babax } \\
\text { and Chirya-3. }\end{array}$ \\
\hline Cluster-II & 13 & $\begin{array}{l}\text { BWL-1793, IEPACA RABE, BWL-9022, HI-1563, } \\
\text { Raj-4083, HD-2864, DBW-14, Seri-82, Dharwar Dry } \\
\text { Othery Egypt, WH-730, Tepoko and PBN-51 }\end{array}$ \\
\hline Cluster-III & 10 & $\begin{array}{l}\text { BWL-1771, Salembo, BWL-0924, CUS/79/PRULLA, } \\
\text { Raj-4037, IC-118737, K-9465, Giza-155, Ariana-66 } \\
\text { andC-306. }\end{array}$ \\
\hline Cluster-IV & 1 & Sonora-64 \\
\hline Cluster-V & 1 & Raj-3765 \\
\hline Cluster-VI & 1 & IC-532653 \\
\hline
\end{tabular}


Table.3 Percent contribution of different characters towards genetic divergence

\begin{tabular}{|l|l|l|l|}
\hline SIN0. & Contribution \% & Ilimes Ranked lst \\
\hline $\mathbf{1}$ & Days to 75\% heading & $0.00 \%$ & 0 \\
\hline $\mathbf{2}$ & Days to 75\% anthesis & $0.00 \%$ & 0 \\
\hline $\mathbf{3}$ & Days to 75\% maturity & $0.00 \%$ & 0 \\
\hline $\mathbf{4}$ & Grain filling duration & $0.00 \%$ & 0 \\
\hline $\mathbf{5}$ & Plant height $(\mathrm{cm})$ & $0.00 \%$ & 0 \\
\hline $\mathbf{6}$ & Peduncle length $(\mathrm{cm})$ & $0.00 \%$ & 0 \\
\hline $\mathbf{7}$ & Spike length $(\mathrm{cm})$ & $0.00 \%$ & 0 \\
\hline $\mathbf{8}$ & Spikelets/ spike & $0.20 \%$ & 1 \\
\hline $\mathbf{9}$ & Grain/ spike & $0.00 \%$ & 0 \\
\hline $\mathbf{1 0}$ & Grain weight/spike (gm) & $0.00 \%$ & 0 \\
\hline $\mathbf{1 1}$ & Tillers/ plant & $0.40 \%$ & 2 \\
\hline $\mathbf{1 2}$ & Biological yield/ plant (gm) & $2.82 \%$ & 14 \\
\hline $\mathbf{1 3}$ & Grain Yield/plot (gm) & $51.01 \%$ & 253 \\
\hline $\mathbf{1 4}$ & 1000 Grain weight (gm) & $0.00 \%$ & 0 \\
\hline $\mathbf{1 5}$ & Canopy temperature depression-I & $21.17 \%$ & 105 \\
\hline $\mathbf{1 6}$ & Canopy temperature depression-II & $1.01 \%$ & 5 \\
\hline $\mathbf{1 7}$ & Canopy temperature depression-III & $2.22 \%$ & 11 \\
\hline $\mathbf{1 8}$ & Canopy temperature depression-IV & $10.28 \%$ & 51 \\
\hline $\mathbf{1 9}$ & Relative water content (\%) & $3.43 \%$ & 17 \\
\hline $\mathbf{2 0}$ & SPAD Value & $7.26 \%$ & 36 \\
\hline $\mathbf{2 1}$ & Harvest index (\%) & $0.20 \%$ & 1 \\
\hline
\end{tabular}

Table.4 Intra and Inter-Cluster Distances

\begin{tabular}{|l|l|l|l|l|l|l|}
\hline & Cluster-I & Cluster-II & Cluster -III & Cluster-IV & Cluster-V & Cluster -VI \\
\hline Cluster-I & 139.51 & 410.95 & 597.46 & 1163.56 & 996.05 & 1879.23 \\
\hline Cluster-II & & 353.12 & 665.03 & 638.41 & 596.43 & 1518.53 \\
\hline Cluster-III & & & 583.84 & 970.10 & 1105.93 & 1325.23 \\
\hline Cluster-IV & & & & 0.00 & 614.64 & 957.17 \\
\hline Cluster-V & & & & & 0.00 & 1924.88 \\
\hline Cluster-VI & & & & & & 0.00 \\
\hline
\end{tabular}

Table.5 Cluster Means for different characters

\begin{tabular}{|l|l|l|l|l|l|l|l|l|l|l|l|}
\hline & DH & DA & DM & GFD & PH & PL & SL & NSS & NGS & GWS & NTP \\
\hline Cluster-I & $\mathbf{8 9 . 8 9}$ & $\mathbf{9 4 . 0 0}$ & $\mathbf{1 3 3 . 4 4}$ & $\mathbf{3 9 . 4 4}$ & $\mathbf{9 7 . 0 9}$ & $\mathbf{3 3 . 7 3}$ & $\mathbf{1 1 . 0 5}$ & $\mathbf{1 9 . 4 2}$ & $\mathbf{5 9 . 0 0}$ & $\mathbf{2 . 5 7}$ & $\mathbf{6 . 3 0}$ \\
\hline Cluster-II & $\mathbf{8 4 . 4 1}$ & $\mathbf{9 1 . 6 4}$ & $\mathbf{1 3 1 . 7 9}$ & $\mathbf{4 0 . 1 5}$ & $\mathbf{9 7 . 0 3}$ & $\mathbf{3 7 . 2 9}$ & $\mathbf{1 1 . 3 3}$ & $\mathbf{1 9 . 0 4}$ & $\mathbf{5 8 . 5 8}$ & $\mathbf{2 . 5 0}$ & $\mathbf{6 . 4 3}$ \\
\hline Cluster-III & $\mathbf{9 0 . 3 0}$ & $\mathbf{9 4 . 5 3}$ & $\mathbf{1 3 2 . 2 3}$ & $\mathbf{3 7 . 9 3}$ & $\mathbf{1 0 5 . 6 9}$ & $\mathbf{3 8 . 6 2}$ & $\mathbf{1 0 . 9 6}$ & $\mathbf{1 9 . 2 0}$ & $\mathbf{5 6 . 0 6}$ & $\mathbf{2 . 3 4}$ & $\mathbf{5 . 8 4}$ \\
\hline Cluster-IV & $\mathbf{7 4 . 0 0}$ & $\mathbf{8 4 . 6 7}$ & $\mathbf{1 2 6 . 6 7}$ & $\mathbf{4 2 . 0 0}$ & $\mathbf{9 0 . 0 7}$ & $\mathbf{3 6 . 8 0}$ & $\mathbf{9 . 2 3}$ & $\mathbf{1 7 . 6 7}$ & $\mathbf{4 2 . 1 3}$ & $\mathbf{1 . 4 1}$ & $\mathbf{5 . 6 7}$ \\
\hline Cluster-V & $\mathbf{8 1 . 3 3}$ & $\mathbf{8 9 . 6 7}$ & $\mathbf{1 3 2 . 0 0}$ & $\mathbf{4 2 . 3 3}$ & $\mathbf{9 5 . 7 3}$ & $\mathbf{3 4 . 8 0}$ & $\mathbf{1 1 . 8 5}$ & $\mathbf{2 0 . 0 0}$ & $\mathbf{5 9 . 3 3}$ & $\mathbf{2 . 4 7}$ & $\mathbf{5 . 6 7}$ \\
\hline Cluster-VI & $\mathbf{9 5 . 3 3}$ & $\mathbf{1 0 1 . 6 7}$ & $\mathbf{1 4 2 . 0 0}$ & $\mathbf{4 0 . 3 3}$ & $\mathbf{1 1 3 . 6 7}$ & $\mathbf{4 4 . 2 0}$ & $\mathbf{9 . 7 4}$ & $\mathbf{2 0 . 6 7}$ & $\mathbf{5 6 . 0 7}$ & $\mathbf{2 . 1 1}$ & $\mathbf{5 . 7 0}$ \\
\hline
\end{tabular}




\section{Continued....}

\begin{tabular}{|l|l|l|l|l|l|l|l|l|l|l|l|}
\hline & BY & GY & TGW & CTD-I & $\begin{array}{l}\text { CTD } \\
\text {-II }\end{array}$ & $\begin{array}{l}\text { CTD- } \\
\text { III }\end{array}$ & $\begin{array}{l}\text { CTD } \\
\text {-IV }\end{array}$ & RWC & SPAD & HI & GY \\
\hline Cluster-I & 22.26 & 2527.00 & 37.72 & 5.68 & 3.70 & 2.65 & 1.22 & 68.31 & 37.94 & 42.56 & $\begin{array}{l}2527.0 \\
0\end{array}$ \\
\hline Cluster-II & 20.59 & 2292.67 & 38.29 & 2.75 & 4.69 & 2.68 & 1.72 & 62.77 & 39.61 & 41.45 & 2292.6 \\
\hline Cluster-III & 19.02 & 2082.73 & 40.51 & 5.21 & 4.29 & 2.55 & 1.35 & 69.93 & 40.76 & 35.85 & 2082.7 \\
\hline Cluster-IV & 13.07 & 1670.67 & 30.48 & 1.40 & 4.93 & 4.65 & 2.43 & 66.65 & 37.00 & 38.24 & 1670.6 \\
\hline Cluster-V & 19.13 & 2351.33 & 36.32 & 0.83 & 4.41 & 2.47 & 3.60 & 62.91 & 67.43 & 36.24 & 2351.3 \\
\hline Cluster-VI & 16.67 & 915.33 & 35.30 & 3.67 & 2.57 & 2.47 & 1.53 & 68.20 & 42.80 & 36.86 & 915.33 \\
\hline
\end{tabular}

DF-Days to 75\%, DA-Days to 75\% anthesis, DM-Days to 75\% maturity, GFD-Grain filling duration, PH-Plant height, PL-Peduncle length, SL-Spike length, NSS- Number of spikelets per spike, NGS-Number of grains per spike, GWS-Grain weight per spike, NTPNumber of tillers per plant, BY-Biological yield per plant, GY- Grain yield/plot, TGW-1000 grain weight, CTD-Canopy temperature depression, RWC-Relative water content (\%), SPAD- Soil-plant analysis development, HI-Harvest index (\%).

Fig.1 Clustering of Genotypes by Tocher Method

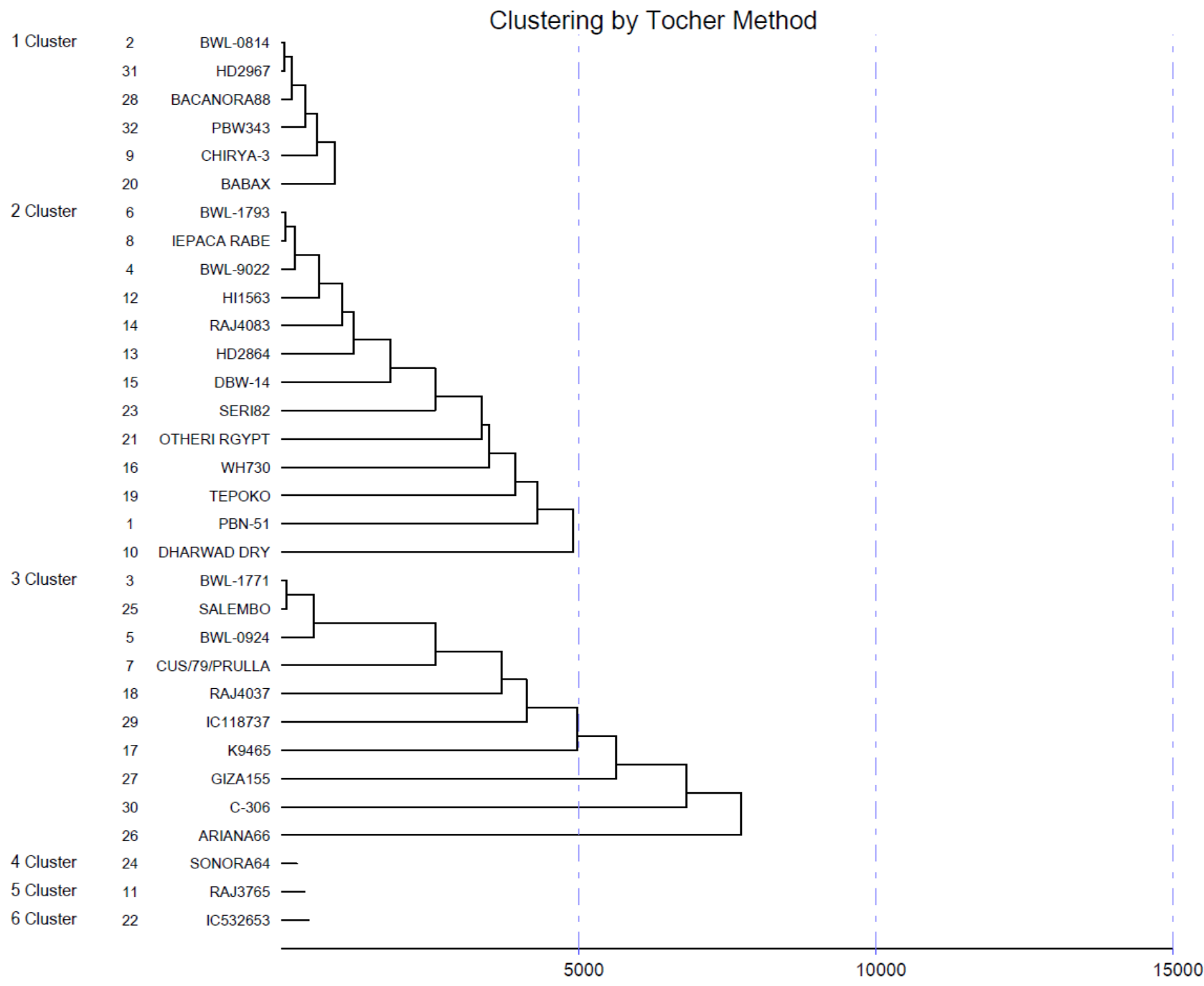


Fig.2 Percent Contribution of Different Characters towards Genetic Divergence

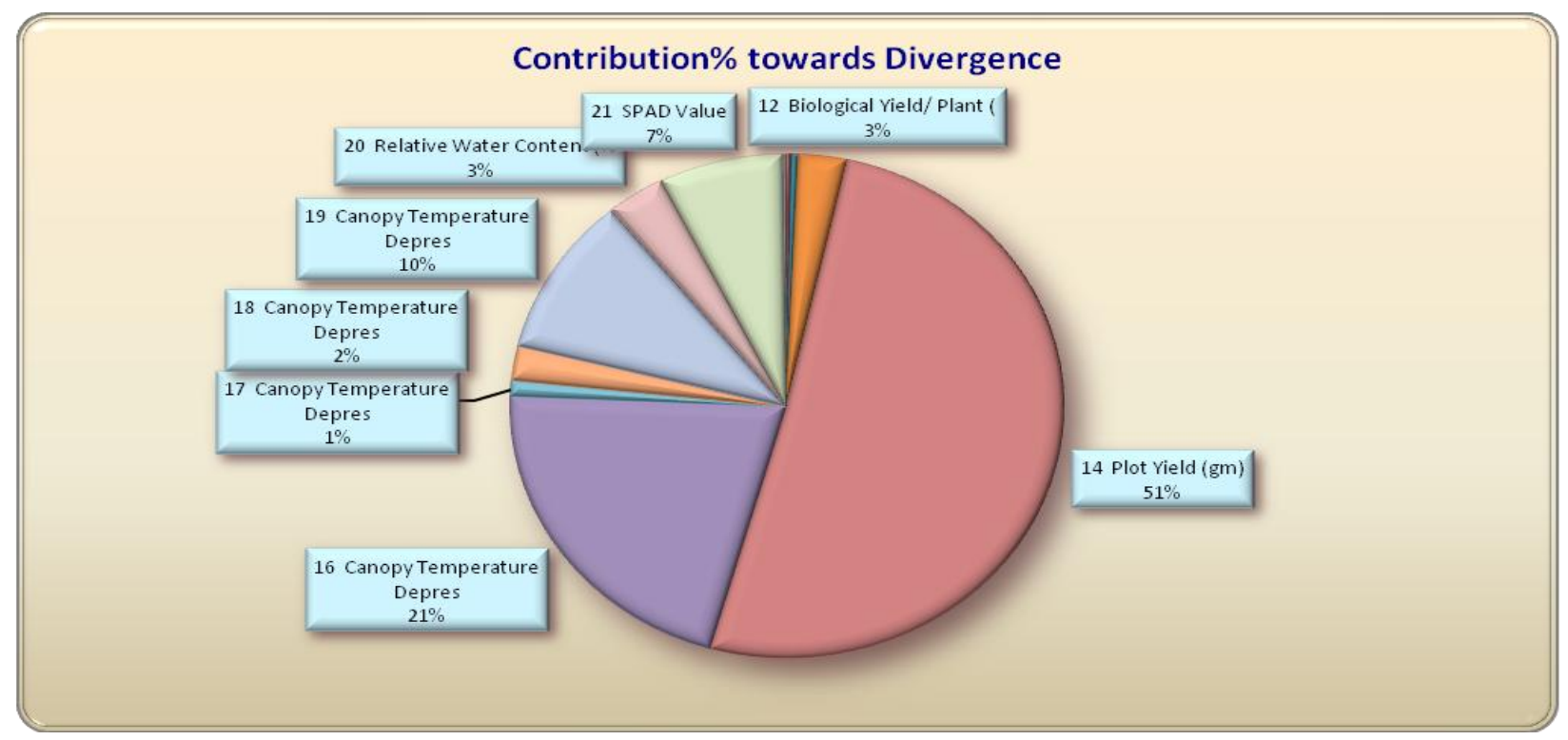

The maximum cluster mean for peduncle length was observed in cluster-VI (44.20) followed by cluster-III (38.62), cluster-II (37.29), cluster-IV (36.80), cluster-V (34.80) and minimum was exhibited by cluster-I (33.73).

The highest cluster mean for spike length was observed in cluster-V (11.85) followed by cluster-II (11.33), cluster-I (11.05), cluster-III (10.96), cluster-VI (9.74) and the lowest was observed in cluster-IV (9.23). The maximum cluster mean for number of spikelets per spike was exhibited by cluster-VI (20.67) followed by cluster-V (20.00), cluster-I (19.42), cluster-III (19.20), cluster-II (19.04) and minimum was in cluster-IV (17.67).The highest cluster mean for number of grains per spike was observed in cluster-V (59.33) followed by cluster-I (59.00), cluster-II (58.58), cluster-VI (56.07), cluster-III (56.06) and the lowest by cluster-IV (42.13).

The highest cluster mean for grain weight per spike was exhibited by cluster-I (2.57) followed by cluster-II (2.50), cluster-V (2.47), cluster-III (2.34), cluster-VI (2.11) and the lowest by cluster-IV (1.41).The maximum cluster mean for number of tillers per plant was observed in cluster-II (6.43) followed by cluster-I (6.30), cluster-III (5.84), cluster-VI (5.70) and the lowest by clusters-IV and V (5.67).The cluster-I have highest cluster mean for biological yield per plant (22.26) followed by cluster-II (20.59), cluster-V (19.13), cluster-III (19.02), cluster-VI (16.67) and the lowest exhibited by cluster-IV (13.07).

The maximum cluster mean for plot yield was observed in cluster-I (2527.00) followed by cluster-V (2351.33), cluster-II (2292.67), cluster-III (2082.73), cluster-IV (1670.67) and the minimum by cluster-VI (915.33). The highest cluster mean for 1000-grain weight was exhibited by cluster-III (40.51) followed by cluster-II (38.29), cluster-I (37.72), cluster-V (36.32), cluster-VI (35.30) and the lowest by cluster-IV (30.48). The cluster-I exhibited highest cluster mean (5.68) for the CTD-I followed by cluster-III (5.21), cluster-VI (3.67), cluster-II (2.75), cluster-IV (1.40) and the lowest by cluster-V (0.83). The highest cluster mean for the character canopy temperature depression-II was exhibited by cluster-IV (4.93) followed by cluster-II (4.69), cluster-V (4.41), cluster-III (4.29), cluster-I (3.70) and the lowest by cluster-VI (2.57).

The maximum cluster mean for the character CTD-III was exhibited by cluster-IV (4.65) 
followed by cluster-II (2.68), cluster-I (2.65), cluster-III (2.55) and the lowest by clusters-V and VI (2.47). The cluster-V exhibited highest cluster mean (3.60) for the CTD-IV (3.60) followed by cluster-IV (2.43), cluster-II (1.72), cluster-VI (1.53), cluster-III (1.35) and the lowest by cluster-I (1.22).

The highest cluster mean for the character RWC (\%) was exhibited by cluster-III (69.63) followed by cluster-I (68.31), cluster-VI (68.20), cluster-IV (66.65), cluster-V(62.91) and the lowest by cluster-II (62.77). The maximum cluster mean for the character SPAD value was exhibited by cluster-V (67.43) followed by cluster-VI (42.80), cluster-III (40.76), cluster-II (39.61), cluster-I(37.94) and the minimum by cluster-IV (37.00). The clusterI exhibited highest cluster mean (42.56) for the character harvest index $\%$ followed by cluster-II (41.45), cluster-IV (38.24), cluster-VI (36.86), cluster-V (36.24) and lowest by cluster-III (35.85).

In conclusion, the most important trait that causing maximum genetic divergence was grain yield per plot and it was responsible for differentiating the genotypes studied.

The highest inter-cluster distance was found between clusters-V and VI (1924.88) suggesting that crossing between the members of these two clusters will lead to development of wide range of genetic variability and breeder will have greater chances to get desired segregants while the lowest inter-cluster distance observed between cluster-I \& II (410.95) indicates that the genotypes in these two clusters were relatively close to each other, exhibiting poor range of genetic variability. Cluster-I exhibited highest cluster means for the characters grain weight per spike, biological yield per plant, plot yield, canopy temperature depression-I and harvest index and cluster-III was marked by highest cluster means for the traits 1000 grain weight and RWC. The genotypes from these two clusters would be promising if selected for hybridization programme for yield contributing as well as physiological traits. Cluster-III, IV and $\mathrm{V}$ exhibited highest cluster mean for physiological traits like RWC, CTD and SPAD value in wheat could also be used in hybridization programmes for physiological traits. Hence, crossing between genotypes belonging to these clusters may result in high heterosis, which could be exploited in crop improvement by plant breeder to get desired transgressive segregants. Inter and intra-cluster distance provide index of genetic diversity between and within clusters. It would be desirable to choose the donor from different clusters. Larger the distance between the clusters better the chances of getting transgressive segregants. These findings suggest that the experimental material had sufficient genetic diversity for yield contributing as well as physiological traits. Diversity in these characters may be exploited through hybridization for the development of superior individuals for yield and physiological traits.

\section{Acknowledgements}

The authors pose sincere thanks to Director, Experiment Station, GBPUAT, Pantnagar for providing necessary facilities for carrying out the investigation and Dr. Johar Singh, Sr. Wheat Breeder, PAU, Ludhiana for providing seed of some of the entries from USAID heat tolerance project.

\section{References}

Arunachalam, V. A. (1981). Genetic distances in plant breeding. Indian J. Genet.4: 226236.

Arya, V.K., Singh J., Kumar L., Kumar R., Kumar P., Chand, P. (2017) Genetic variability and diversity analysis for yield and its components in wheat (Triticum aestivum L.). Indian J. Agric. Res.; 51(2):128-134.

Bhatt, G.M. (1970). Multivariate analysis approach to selection of parents for hybridization aiming at yield component in self-pollinated crops. Aus J. Agric. Res.21:1-7.

Carves, B.F., Smith, E.L, and England, H.O. 
(1987). Regression and cluster analysis of environmental responses of hybrid and pure line winter wheat cultivars. Crop Sci 27: 659-664.

Dobariya, K.L., Ribadia, K.H., Padhar, P.R., Ponkia, H.P. (2006). Analysis of genetic divergence in some synthetic lines of bread wheat (Triticum aestivum L.). Advances in Plant Sciences. 19(1): 221225.

ICAR-IIWBR，2018. Director's Report of AICRP on Wheat and Barley Improvement Project 2017-18. Ed: G. P. Singh, ICAR-Indian Institute of Wheat and Barley Research, Karnal, India. p.87.

Jaiswal, J.P., Arya, M., Kumar, A., Swati and Rawat, R.S. 2010. Assessing genetic diversity for yield and quality traits in indigenous bread wheat germplasm. Electronic J. of Plant Breeding. 1(4): 370- 378.

Joshi, A.B., Dhawan, N.L. (1966) Genetic improvement of yield with special reference to self-fertilizing crops. Ind J.Genet.and Plant Breed. 26: 101-113.

Joshi, B.K., Mudwari, A., Bhatta, M.R. and Ferrara, G.O. (2004). Genetic diversity in Nepalese wheat cultivars based on agromorphological traits and coefficients of parentage. Nep Agric Res J.5: 7-17.

Khare M., Rangare N.R. and Singh, R.P. (2015). Evaluation of genetic diversity in Mexican wheat (Triticum aestivum L.) genotypes for quantitative and qualitative traits. International Journal of Plant Protection, 8(1):77-80.

Kumar, B., Lal, G.M., Ruchi and Upadhyay, A. (2009). Genetic variability, Diversity and association of quantitative traits with grain yield in bread wheat (Triticum aestivum L.). Asian Journal of
Agricultural Sciences 1(1):4-6.

Mahalanobis, P.C. (1936). On the generalized distance in statistics. Proc. Nat. Inst. Sci. India, 2: 49-55.

Mohammdi, S.A. and Prasanna, B.H. (2003). Analysis of genetic diversity in crop plant salient statistical tools and considerations, Crop Sci.,43(4):1235-1248.

Rahman M.S., Hossain M.S., Akbar M.K., Islam M.S. and Ali L. (2015). Genetic divergence in spring wheat genotypes (Triticum aestivum L.). Eco- friendly Agricultural Journal, 8(1): 01-03.

Rao, C.R. (1952). Advanced statistical method in biometric research. John Wiley and Sons Inc. New York, USA.

Shekhawat U.S., Vijay P. and Singhania D.L. (2001). Genetic divergence in barley (Hordeum vulgare L.) Indian J. Agric.Res. 35(2):121-123.

Singh, S.K., Singh B.N., Singh, P.K. and Sharma, C.L. (2006). Genetic divergence of exotic germplasm lines in wheat $(T$. aestivum L.). Indian J. Plant Genet.Resources. 19 (2):218-220.

Singh D., Singh S.K., Singh K.N. (2009). Diversity of salt resistance in a large germplasm collection of bread wheat (Triticum aestivum L.). Crop Improvement, 36(1): 9-12.

Tewari, R., Jaiswal, J.P., Gangwar, R.P. and Singh, P.K. (2015). Genetic diversity analysis in exotic germplasm accessions of wheat (Triticum aestivum L.) by cluster analysis. Electronic Journal of Plant Breeding, 6(4): 1111-1117.

Zodoks, J.C., Chang, T.T. and Konzak, C.F. (1974). A decimal code for the growth stages of cereals. Weed Research, 14:415421.

\section{How to cite this article:}

Santosh, J.P. Jaiswal, Anupama Singh and Naveen Chandra Gahatyari. 2019. Genetic Diversity Analysis in Bread Wheat (Triticum aestivum L.em.Thell.) for Yield and Physiological Traits. Int.J.Curr.Microbiol.App.Sci. 8(02): 3059-3068. doi: https://doi.org/10.20546/ijcmas.2019.802.358 